\title{
Keys to their own voices: social tags for a dementia ontology as a human right
}

\author{
Diane Rasmussen Pennington, University of Strathclyde
}

Introduction

Dementia encompasses a range of incurable brain conditions such as Alzheimer's disease, which affected 47 million people worldwide in 2015, a figure that is expected to triple by 2050. It is therefore a worldwide public health priority (World Health Organization, 2017). While the symptoms differ among individuals to some extent, the World Health Organization (WHO) defines them as follows:

- difficulties with everyday tasks

- confusion in familiar environments

- difficulty with words and numbers

- memory loss

- changes in mood and behaviour.

Caring for people living with dementia (PLWD) is a burdensome task and it tends to fall to family members, which causes them considerable stress. The WHO's Global Action Plan on the Public Health Response to Dementia 2017-2025 focuses on dementia prevention as well as on improving the lives of PLWD and their carers so that they 'live well and receive the care and support they need to fulfil their potential with dignity, respect, autonomy and equality'. The United Nations has called for dementia to be a public health priority in all countries (UN News Centre, 2015).

This chapter will first explore the uniquely challenging context of information needs and dementia. It will then use dementia as a case study to demonstrate how user-generated hashtags, or other forms of surrogate representation, could be applied in a linked data environment in order to improve access to care, resources, people and other needs.

\section{Entities in the dementia ontology}

Because just one PLWD affects and, conversely, is affected by, a range of entities, it is perhaps useful to consider some of the different entities and their unique contexts and needs individually. It is then easier to see how they intertwine within what this chapter calls a dementia ontology. An ontology is broadly defined as 'a formal representation of knowledge with rich semantic relationships between terms' (Stuart, 2016, 12). A dementia ontology, 
then, is a representation of knowledge with relationships between entities that are somehow related to a PLWD.

\section{PLWD}

In relation to the emphasis on person-centred care in dementia (Brooker, 2003), the PLWD should be placed at the centre of this dementia system or ontology. It is essential to view the PLWD as a person rather than as a patient, so as not to marginalise the person and their needs. Additionally, respectful language should be chosen when discussing dementia to respect the PLWD's rights and dignity; for example, do not call them 'sufferer', 'senile', or 'burden' (DEEP, 2015).

Clinical or biomedical language dominates the literature, research and care of PLWD. While evidence-based medical treatment is obviously necessary, PLWD also have a range of other needs, including socialisation, whether with family and friends or other PLWD), psychological counselling and support and assistance with managing their daily lives. Recently, new approaches have been taken to help improve the quality of life for PLWD, such as music therapy for enjoyment (Aldridge, 2000; Riley, Alm and Newell, 2008) and trained dogs for companionship and assistance with tasks of living (Swall et al., 2015). Some research has found a shorter survival time for PLWD when they have limited social networks, so interaction with others is important (Santini et al., 2015). However, since PLWD's symptoms evolve throughout the course of the condition, including demonstrable changes in general awareness (Clare et al., 2008), their needs for care, interaction and information also change constantly.

Research is obviously important for PLWD, but a human rights-based approach to dementia (Alzheimer Scotland, 2017), which is increasing in importance as a result of effective advocacy, calls for PLWD to participate in co-produced research as well as directly receive the benefits of the research. In the early stages of dementia, it might be advisable to consent to research that might take place in the future, since the ability to provide consent will change over time (Pierce, 2010).

\section{Carers}

Just as PLWD change throughout the course of the disease, the roles of carers, who are usually close family members such as the PLWD's spouse or children, also change (Berry, Apesoa-Varano and Gomez, 2015). The transitions are quite marked in the carer's context. A carer, for example, might move from occasionally checking in on the PLWD, to quitting their job in order to look after the PLWD 24 hours per day, to moving the PLWD to a care home when it becomes too much for one carer to handle, then to hospice care and then final 
bereavement. In most places, family members caring for the PLWD full-time are not recognised as having a job, even though they are typically exhausted and overwhelmed (Bond, Clark and Davies, 2003). This has been called role entrapment, because they cannot take breaks from their caregiving roles without potentially disastrous consequences (Lewis, 2015), such as the PLWD wandering out of the house and getting lost. Health and social care services might or might not be available, depending on a range of factors such as geographic location, socioeconomic status and stage of the condition (Robinson et al., 2014). A range of factors may determine whether a carer chooses to use the services available (Toseland et al., 2002).

\section{Health professionals}

The dementia-related responsibilities of health professionals, such as social workers and primary care physicians, can pose challenges. While highly trained in many areas of health, health professionals may not know the best ways to communicate with PLWD and their families, especially in the context of relationships (Cox and Pardasani, 2013). Since dementia is a complex condition that takes time to diagnose and there is a stigma attached to it, the diagnosis itself may cause conflict between the doctor, the PLWD and their family (Hansen et al., 2008, 1776). Additionally, physicians use a range of information sources complementarily to treat their patients, including textual, physical and social sources (Isah and Byström, 2016). These information practices are likely to provide comprehensive care, but they also add to the amount of information work physicians must do on a daily basis.

\section{Employers and workplaces}

Certain organizations and communities, such as workplaces, will feel the effects of PLWD. It is beneficial for people to stay employed in a challenging role for as long as possible because this may reduce the chances of dementia (Wilson, 2005), or even reduce symptoms after diagnosis. In the early stages of the condition, employers and work colleagues may not know how to recognise it as a potential medical issue (Lurati, 2014; McNamara, 2014) and may simply think the employee is aging or becoming forgetful. However, while cognitive changes occur in the normal ageing process, dementia is not a normal outcome of ageing. This is why colleagues of PLWD need training, including what the PLWD will need (McNamara, 2014; Pennington, 2016). Additionally, employed carers need to communicate with their employers about their challenging personal situation (Ritchie et al., 2015).

\section{Information needs and sources within the dementia ontology}

Information scientists have an opportunity to take an active role in dementia care by 
assisting with meeting information needs; in particular, they need to partner with other researchers or conduct complementary research, given the focus in information science 'on linking individuals with a particular information need to appropriate, specific information sources' (Erdelez, Howarth and Gibson, 2015). However, issues related to cognition, information organization and representation must also tie into these efforts, as explored later in this chapter.

From a human rights perspective, PLWD have the right to be informed about their condition and their lives (Hertogh et al., 2004). PLWD 'need information to support autonomy in making decisions and in acting on those decisions' (Clarke, Alexjuk and Gibb, 2011, 237). When provided, this information should be specific, clear, accessible and easy to understand. However, information services for PLWD and their carers, especially official sources such as physicians and related services, are limited (Corbett and Ballard, 2011). Information may also be presented in difficult clinical language, which is how much information about dementia is communicated, as mentioned previously. Despite this, in the early stages, PLWD are encouraged to take on the role of self-management, including educating themselves about the condition, but the benefit from this appears to be limited (Quinn et al., 2014). Although PLWD receive information from many sources, including their bodies, that things are changing (Yates, 2015; Polkinghorne and Chambers, 2016), it might be difficult for them to identify or to communicate what information they need, given the cognitive changes that take place as a result of the condition. Challenges with using and understanding language are frequently a symptom.

Carers also face unmet information needs. It is difficult for carers to find information and they may not know what types of information they need, or what information is available. In one study, carers who sought help about assistive technologies for dementia care had difficulty obtaining information about what technologies were available (Gibson et al., 2015). The 'self-management' role may transfer from the PLWD to their carer as the condition evolves (Quinn et al., 2014).

Additional information and education is needed to reduce the stigma and negativity in representations of dementia that exist in media messages and are held by policy makers and the general public. This can start with simple changes, such as how dementia symptoms are labelled; there are very different connotations between cognitive change and cognitive decline, for example. The general notion for the public, some policy makers and the media is that PLWD do not have their minds any longer and that they are seen as doomed and socially dead (Van Gorp and Vercruysse, 2012; Dupuis et al., 2016). Along with changing language 
connotations, visuals within the media can also make a difference: 'Images should be used in context. For example, when talking about someone trying to live a positive life, use an image that reflects the whole person rather than a fading face or wrinkled hands' (DEEP, 2015). While these negative messages could potentially cause PLWD and their carers to worry about an inevitable decline and a death sentence, support from their peers helps them challenge these views (Keyes et al., 2016).

\section{Information engagement for PLWD within the dementia ontology}

The opportunities with which PLWD and, quite possibly, others in the ontology, engage with information sources seem to affect their quality of life and well-being. Engagement has many definitions and is used often to define how people interact socially with digital media (O’Brien and Cairns, 2016), but it could involve any method in which people provide, receive and interact with information and social sources of information. In the context of dementia, social inclusion is important, both in the workplace, for as long as possible, and within the PLWD's local community (Robertson and Evans, 2015).

The networked environment also offers engagement opportunities for PLWD. While some might believe that PLWD would not be able to use online technologies due to cognitive functioning concerns, this is not always the case, especially in the earlier stages. Online social support for people experiencing health challenges, including mental health, has been shown to be useful for well-being and peer information sources (Yan and Tan, 2014). Online, peers facing similar medical situations work together to analyse other sources, potential treatments and apparent authorities (Neal and McKenzie, 2011; Miller, 2017). Miller analysed blog posts written by PLWD to determine where they ascribed the most authority; it rested most highly within their peer community,

with PLWDs expressing a desire to collaborate in the exchange of knowledge with other PLWDs due to the importance placed on lived experience and the sense of a shared indepth knowledge that those who do not have dementia are incapable of fully appreciating (Miller, 2017, ii)

This result is similar to a finding in Neal and McKenzie's (2011) study of blogs written by women living with the chronic illness endometriosis; bloggers considered other women with endometriosis to be reliable authorities. Researchers have suggested that in the future, developers could create systems that allow online consumers of health information to evaluate its quality (Zhang, Sun and Zie, 2015). Additionally, the need for PLWD to be involved in the development of systems or online sources meant for them to use is essential 
(Span et al., 2013), preferably in a co-design situation, in which the PLWD are actively involved in all stages of the design and development processes (Rodgers, 2017).

\section{Surrogates, social tags and the dementia ontology}

People who discuss dementia on social media apply social tags as referents to dementia-related topics and events, including hashtags, such as \#dementia, \#Alzheimers, \#alz, \#caregiver, \#WorldAlzheimersDay and \#MemoryWalk. When used in large numbers for searching or browsing, these tags serve as a form of user-generated, controlled vocabulary: they can link users to other posts about dementia or a dementia-related events and could eventually serve more fully as linked data facilitators. How might social tags relate to a dementia ontology that would allow the multitude of different groups within the ontology to understand and connect with one another?

Because dementia varies from person to person and day to day and PLWDs' interactions with the world change over time (Vernooij-Dassen et al., 1998), it is difficult to define, with or without social tags and even with or without an ontology. Figure 8.1 shows one possible branch of a dementia ontology, with the PLWD at the centre. This ontology is not highly structured, but it shows the relationships between PLWD and the different entities with which they interact. Several branches of additional ontological relationships would branch out from this starting point; for example, we would want to see the interactions between professional caregivers, health professionals, friends and family and other entities, as well as how the relationships play out between each other.

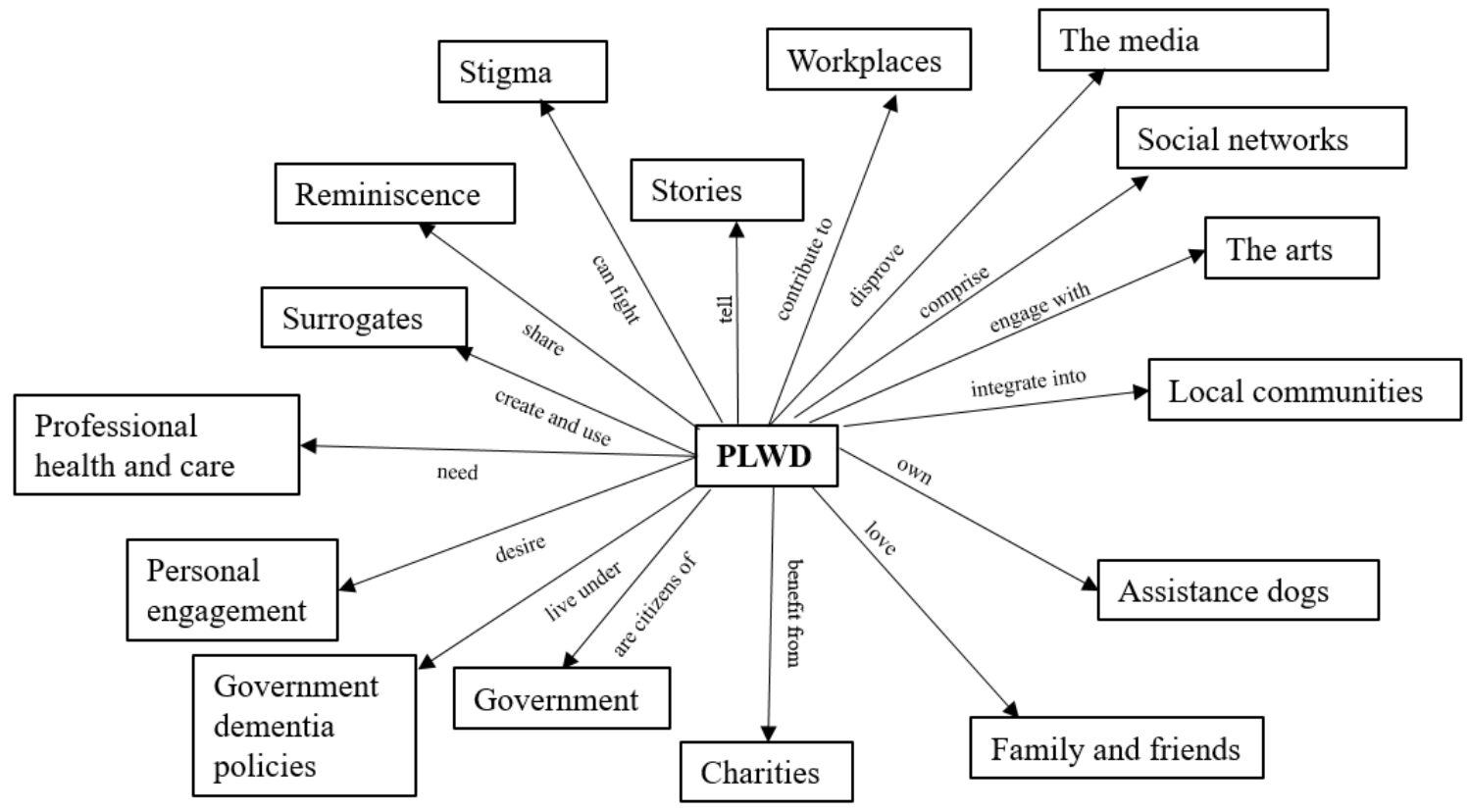

Figure 8.1 A start of a dementia ontology, with a PLWD at the centre 
In addition to the necessity of placing the PLWD at the centre, this ontology represents the necessary integrated approach to health and social care involving formally and informally instituted entities. Information sharing takes place between and among all these entities and ultimately the PLWD benefits. For example, the media increases stigma, stigma can be reduced by family and friends, family and friends can influence government dementia policies and so on. This ontological approach can emphasise the entire system of entities that influence the experiences of PLWD. From theoretical and human rights perspectives, it reminds everyone to keep the PLWD as the focus. If this ontology were a framework for an actual linked data implementation, it would model how all sources of shared information can and should be connected. This would maximise the chances that any entity within the ontology will encounter information from any other entity when all of their information sources are semantically linked.

This chapter has already demonstrated how the different entities in a dementia ontology speak different languages. Within the domain of knowledge organization and representation, the notion of the surrogate as a language occurs frequently. In a traditional sense, the domain speaks of a surrogate as a standardised, representative metadata record that describes and refers to the actual document, such as a MARC (Machine Readable Cataloguing) record in an OPAC (online public access catalogue) for a monograph (Chan and Salaba, 2016). However, this standardised approach limits the ability of different groups to describe and retrieve items in ways that are meaningful to them. It also further marginalises already marginalised groups. This marginalisation occurs in many contexts with respect to information seeking and retrieval. For example, McTavish, Neal and Wathen (2011) found that the Medical Subject Headings (MeSH) may support a gender-neutral view of violence in its approach to knowledge organization, even in light of the many concerns related to violence against women.

What would happen if the social tags were not textual, but rather visual or sonic? In future systems, could tags be photographs, videos, or music? For example, a relaxing music clip could be a tag that would link to other relaxing music; these linked clips might help a PLWD experiencing anxiety or insomnia. A tag comprised of an infant's photograph could elicit reminiscence and link to other tags containing reminiscence potential. Some inspiration for this idea originates from the work of Lynne Howarth and her colleagues, who have explored the role of surrogate items with marginalised groups, particularly PLWD. In a general sense, Howarth explored how the surrogate can be rethought to construct space for narratives of marginalised voices, to shift the focus from consistency to commonality 
(Howarth and Olson, 2013). In her study of surrogates in dementia, Howarth explores whether the notion of a non-fixed surrogate can give voice to cognitively disabled PLWD by rethinking our organizational structures for surrogates and representation (Howarth, 2014) because PLWD process verbal communication and text differently (Pennington, 2016). Howarth's empirical work asked, 'when memory and/or language are impaired, how does such contextualizing and categorizing occur?' (Howarth and Hendry, 2011). In this research, non-textual or non-verbal surrogates that reminded PLWD of their life experiences, such as favourite foods or photos of their families, enhanced memory and recall. Howarth suggested future research into designing classification and categorisation systems for PLWD to help meet their information needs. Others have discussed the importance of non-textual items, such as pictures, for reminiscence therapy, memory aids and essential information such as signage in public spaces (Bate, 2014). As mentioned previously, these surrogates could become tags in future social tagging systems. At present, tags themselves are only textual, even when they describe non-textual items like photographs, but perhaps representing a photograph with a visual tag would increase the engagement of PLWD and less semantic meaning would be lost in the representation (O'Connor and Wyatt, 2004).

It is essential to consider the non-verbal and non-textual aspects of these surrogates. Typical text-based social tags can serve as search and browse tools, but they serve also as storytelling aids or commentary on social media. For example, \#justforfun or \#SundayMorning may not assist users too much in retrieving relevant posts, but they clearly serve a communicative function for the person who created the posts. Language can be a primary challenge for PLWD, so they may not be able to write relevant hashtags to communicate their lives, but they do have other means of communicating about their lives. Evans, Robertson and Candy (2016), for example, gave cameras to PLWD who had recently returned to the workplace after receiving their diagnosis. The photographs they took of their work environment communicated their own stories, frustrations, social connections and daily scenes, just as social tags do for many social media users. Involvement in creating art, such as acting in a play or painting a scene, can help PLWD communicate narratives as well (Dupuis et al., 2016). Clarke and Bailey’s 2016 study explored how PLWD experienced life and found that they placed a strong emphasis on the roles of social and physical belongingness. The paper discussed these relationships in the context of narrative citizenship in the participants' social and physical places, which 'offers an approach that enhances individualised yet collective understandings of living with dementia' (Clarke and Bailey, 2016, 434). PLWD can communicate these understandings in many ways. 
Several initiatives are in process to allow PLWD to express their experiences online in their own ways. Dementia Diaries (dementiadiaries.org), for example, 'is a UK-wide project that brings together people's diverse experiences of living with dementia as a series of audio diaries' (Dementia Diaries, n.d.) The diaries are available on the website for viewing and listening. A set of provocative videos on a Vimeo channel called Living with Dementia (vimeo.com/channels/1148563/188113371), supported by publicly-funded research in the UK, challenges people to rethink the perceptions and perspectives of PLWD. Miller (2017) performed a discourse analysis of blog posts written by PLWD to understand their information needs. Online artefacts such as blog posts would benefit from social tags provided by PLWD - as well as carers, health professionals, families and others involved in the dementia ontology - which truly involves everyone, because dementia is a worldwide health crisis.

Although Web platforms do not allow for a truly diverse range of social tags, at least in terms of non-textual format, they are worthy of development. The semantic web and linked data are being conceptualised and implemented in the right spirit in order to do this. This is because the semantic web is meant to "collect Web content from diverse sources, process the information and exchange the results with other programs' (Berners-Lee, Hendler and Lassila, 2001, 34). The 'sources' could be the groups mentioned above; linked data could allow these groups to communicate and connect within their own groups, with other groups and about a series of entities. Social tags take different forms when they originate from different entities within the dementia ontology presented because various groups use differing terms for the same things. For example, \#sundowning to a health practitioner could be \#ConfusedAtNight to a family caregiver. Linked data has the potential to connect these tags semantically, which would result in the clinician encountering experiences of the family, while the family could then more easily find professional information about their PLWD's evening behaviour.

Linked data applications such as Google's Knowledge Graph, which retrieves and cohesively presents information from a variety of sources related to the user's search, (www.google.com/intl/bn/insidesearch/features/search/knowledge.html) do not seem to work with any type of social tags to produce unified results. Figure 8.2, for example, shows the UK's Google search results for the term Alzheimer. Even after incorporating the Knowledge Graph result on the right-hand side, which is a linked data application, the featured results are from (a) the news media and (b) UK third-sector organizations for ageing and health conditions. The voices of the PLWD are not necessarily present; while these sources are 
acting on their behalf, they may not be representative of the PLWDs' voices. If social tags from the various entities within the dementia ontology could be incorporated into Knowledge Graph's search results, this would elevate the voices of everyone involved and ultimately improve access to a broad range of information that could result in better care and a more satisfactory quality of for PLWDs.

$<$ Fig 8.2 near here $>$

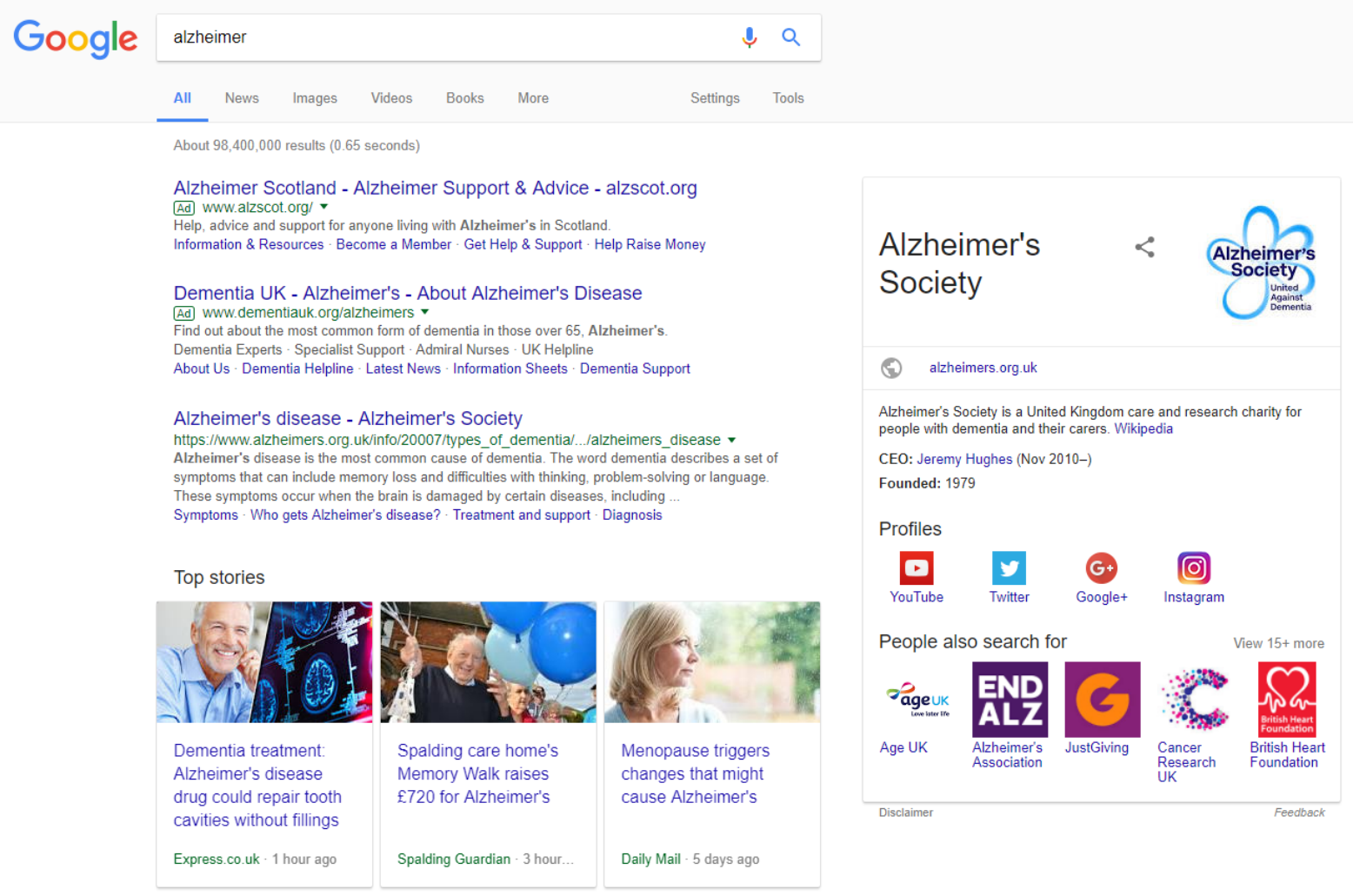

Figure 8.2 Google's search results for the term 'Alzheimer'

\section{Conclusion: human rights, social tags and the dementia ontology}

The human-rights-based approach to dementia and dementia care reminds us that PLWD, just as anyone else with a disability, have legal protection from discrimination and abuse. 'People with dementia have the same civil and legal rights as everyone else' according to the document Our Dementia, Our Needs (Hare, 2016, 8). This same document states that in the UK, if PLWD 'can't understand the information provided by a health or care organization, or if you have specific communication needs, you can cite the Accessible Information Standard and ask them to make improvements' (Hare, 2016, 5). The same is true for online information description and access. PLWD must be able to describe and access online information in ways that make sense and are useful to them. This includes providing the option to add social tags that describe information in their terms.

Social tags may not always be solely presented in textual format; especially as social 
media platforms continue to develop technologically, we may see the ability to use a range of types of individualised user-assigned surrogates in the near future, including photos, videos, spoken words, or tactile objects such as favourite possessions serving as social tags. Because non-textual forms of information such as music and visuals tend to be more easily understandable by PLWD than written words, they should be considered as a future option for social tags that would lead to semantically-based findability. For example, if a PLWD wanted to find information about doing art projects that have the potential to improve their cognition, a tag for the topic could be an instructional video, a spoken podcast on art by another PLWD, background music for painting, or a photograph of a paintbrush. While it might seem difficult to conceptualise non-textual items serving as semantically meaningful tags, it seems likely given the ever-increasing number of multimedia objects posted on social media. Social tags may eventually also be able to serve as connectors in linked data settings, so that information sources related to dementia represent the many individuals, communities and contexts that require information about it. Web technologies should be developed that would automatically extract social tags from various sources and insert them as the predicate in the subject-predicate-object RDF (Resource Description Framework) triple store format that allows for online data interchange (RDF Working Group, 2014). While RDF requires all data to be represented as URIs, it would be a straightforward task to obtain URIs for social tags since they exist on the web. The tag-based URIs would then link together predicates and objects that would not otherwise be found due to the dispersion of different information sources and the vocabularies used by their respective groups. The ability for PLWD and others within a dementia ontology, such as carers, to describe and retrieve online information, whether for treatment options or for social connection, is a human right and therefore protected by national and international laws pertaining to disability and equality.

This chapter has reflected on the opportunities that a comprehensive dementia ontology with the PLWD at the centre, as well as the employment of social tags within a linked data framework, could provide to PLWD and those around them. This approach could bring about a broader range of information encountered to entities looking online and on social media for information and support related to dementia. This would maximise the ability of entities within the system to make more informed decisions about treatment and lifestyle options, apply scientific evidence to practice, find social and emotional support, enhance cognitive abilities and ultimately improve the quality of life of PLWD through dementia-friendly access to dementia-friendly information with the use of RDF-linked tags in multiple formats. 
Consider the words of May, a PLWD who was a participant in Kotai-Ewers' (2000) study about the narratives of PLWD as told in their own words. How might appropriately implemented social tags and linked data applications have helped her?

I just want to be at home.

I have a right to this part

of the end of my life.

Yes, I am wringing my hands. I can't cope.

I have a right to a life of my own.

I am really very angry.

I just want to be at home - and be myself.

Do you have any ideas?

As a starting point for thinking about how May’s narrative could be represented by different types of tags, Figure 8.3 presents some visuals that might represent her feelings from various domains. Imagine each photo as a social tag that could link to related ideas and information. Does this help bring May's story to life?

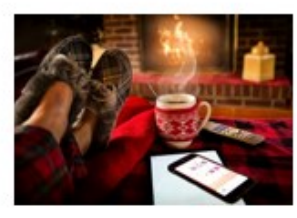

I just want to be at home

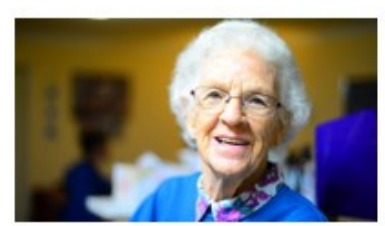

I have a right to this part of the end of my life.

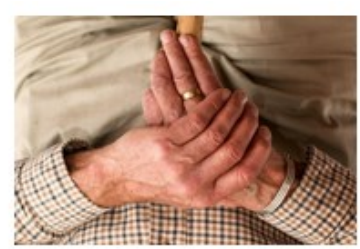

Yes, I am wringing my hands. I can't cope.

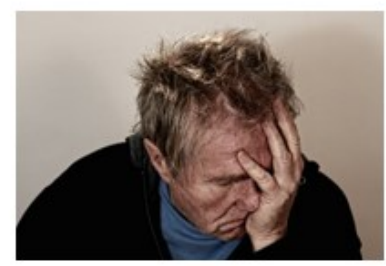

I am really very angry.

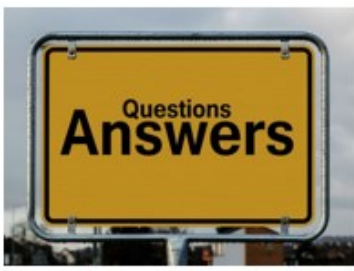

Do you have any ideas?

Figure 8.3 May's narrative represented in pictures that could also serve as linked social tags in future systems

\section{References and further reading}

Aldridge, D. (ed.) (2000) Music Therapy in Dementia Care: more new voices, Jessica Kingsley.

Alzheimer Scotland (2017) A Human Rights-Based Approach to Dementia, 
www.alzscot.org/campaigning/rights_based_approach.

Bate, H. J. (2014) Too Late to Learn to Drive: dementia, visual perception and the meaning of pictures, Pictures to Share.

Berners-Lee, T., Hendler, J. and Lassila, O. (2001) The Semantic Web, Scientific American, 284, 34-44.

Berry, B., Apesoa-Varano, E. C. and Gomez, Y. (2015) How Family Members Manage Risk Around Functional Decline: the autonomy management process in households facing dementia, Social Science \& Medicine, 130, 107-14.

Bond, M. J., Clark, M. S. and Davies, S. (2003) The Quality of Life of Spouse Dementia Caregivers: changes associated with yielding to formal care and widowhood, Social Science \& Medicine, 57, 2385-95.

Brooker, D. (2003) What Is Person-Centred Care in Dementia?, Reviews in Clinical Gerontology, 13, 215-22.

Chan, L. M. and Salaba, A. (2016) Cataloging and Classification: an introduction, Rowman \& Littlefield.

Clare, L., Rowlands, J., Bruce, E., Surr, C. and Downs, M. (2008) 'I Don’t Do Like I Used to Do': a grounded theory approach to conceptualising awareness in people with moderate to severe dementia living in long-term care, Social Science \& Medicine, 66 , $2366-77$.

Clarke, C. L. (2011) Editorial: Information and Dementia: complexity and the obvious, International Journal of Older People Nursing, 6, 216.

Clarke, C. L., Alexjuk, J. and Gibb, C. E. (2011) Information in Dementia Care: sense making and a public health direction for the UK?, International Journal of Older People Nursing, 6, 237-43.

Clarke, C. L. and Bailey, C. (2016) Narrative Citizenship, Resilience and Inclusion with Dementia: on the inside or on the outside of physical and social places, Dementia, 15, 434-52.

Corbett, A. and Ballard, C. (2011) Information Provision Services in Dementia Care, International Journal of Older People Nursing, 6, 217-26.

Cox, C. B. and Pardasani, M. (2013) Alzheimer's in the Workplace: a challenge for social work, Journal of Gerontological Social Work, 56, 643-56.

DEEP (2015) Dementia Words Matter: guidelines on language about dementia, http://dementiavoices.org.uk/wp-content/uploads/2015/03/DEEP-GuideLanguage.pdf. 
Dementia Diaries (n.d.) About the Project, https://dementiadiaries.org/about-the-project.

Dupuis, S. L., Kontos, P., Mitchell, G., Jonas-Simpson, C. and Gray, G. (2016) Re-claiming Citizenship through the Arts, Dementia, 15, 358-80.

Erdelez, S., Howarth, L. C. and Gibson, T. (2015) How Can Information Science Contribute to Alzheimer's Disease Research? In Proceedings of the Annual Meeting of the Association for Information Science \& Technology (Annual Meeting 2015), St. Louis, Missouri, USA, ASIS\&T, https://www.asist.org/files/meetings/am15/proceedings/openpage15.html.

Evans, D., Robertson, J. and Candy, A. (2016) Use of Photovoice with People with Younger Onset Dementia, Dementia, 15, 798-813.

Gibson, G., Dickinson, C., Brittain, K. and Robinson, L. (2015) The Everyday Use of Assistive Technology by People with Dementia and Their Family Carers: a qualitative study, BMC Geriatrics, 15, https://doi.org/10.1186/s12877-015-0091-3.

Hansen, E. C., Hughes, C., Routley, G. and Robinson, A. L. (2008) General Practitioners' Experiences and Understandings of Diagnosing Dementia: factors impacting on early diagnosis, Social Science \& Medicine, 67, 1776-83.

Hare, P. (2016) Our Dementia, Our Rights, http://dementiawithoutwalls.org.uk/wpcontent/uploads/2016/10/Our-dementia-Our-rights-booklet.pdf.

Hendry, E. and Howarth, L. C. (2013) Memory, Truth and Storytelling: evoking narrative from individuals with mild Alzheimer's Disease. In Proceedings of the Annual Conference of the Canadian Association for Information Science, Victoria, British Columbia, Canada, CAIS/ACSI, http://www.caisacsi.ca/ojs/index.php/cais/article/viewFile/833/755.

Hertogh, C. M., The, B. A. M, Miesen, B. M. and Eefsting, J. A. (2004) Truth Telling and Truthfulness in the Care for Patients with Advanced Dementia: an ethnographic study in Dutch nursing homes, Social Science \& Medicine, 59, 1685-93.

Howarth, L. C. (2014) Drawing Clocks Without Time: Alzheimer's, marginalization and the liberatory potential of object memoir. In Proceedings of the Annual Conference of the Canadian Association for Information Science, St. Catharines, Ontario, Canada, CAIS/ACSI, https://journals.library.ualberta.ca/ojs.cais-acsi.ca/index.php/caisasci/article/view/886/799.

Howarth, L. C. and Hendry, E. (2011) Recovering Memory: sense-making and recall strategies of individuals with mild cognitive impairment. In Proceedings of the Annual Meeting of the Association for Information Science \& Technology (Annual 
Meeting 2011), New Orleans, Louisiana, USA, ASIS\&T, http://www.asis.org/asist2011/posters/237_FINIAL_SUBMISSION.doc.

Howarth, L. C. and Olson, H. (2013) Surrogates, Voice and Narratives from the Margins. In Proceedings of the Annual Conference of the Canadian Association for Information Science (CAIS/ACSI), http://www.caisacsi.ca/ojs/index.php/cais/article/view/834/756.

Isah, E. E. and Byström, K. (2016) Physicians' Learning at Work through Everyday Access to Information, Journal of the Association for Information Science \& Technology, 67, $318-32$.

Keyes, S. E., Clarke, C. L., Wilkinson, H., Alexjuk, E. J., Wilcockson, J., Robinson, L., Reynolds, J., McClelland, S., Corner, L. and Cattan, M. (2016) 'We're All Thrown in the Same Boat . . .': a qualitative analysis of peer support in dementia care, Dementia, $15,560-77$.

Kotai-Ewers, T. (2000) Working with Words: people with dementia and the significance of narratives. In Aldridge, D. (ed.) Music Therapy in Dementia Care, Jessica Kingsley Publishers, 63-80.

Lewis, L. F. (2015) Caregiving for a Loved One with Dementia at the End of Life: an emergent theory of rediscovering, American Journal of Alzheimer's Disease \& Other Dementias, 30, 488-96.

Lurati, A. R. (2014) Recognizing Early Dementia in the Workplace: a case study, Workplace Health \& Safety, 62, 94-5.

McNamara, G. (2014) Dementia and the Workplace, Occupational Health, 66, 27-30.

McTavish, J., Neal, D. R. and Wathen, C. N. (2011) Is What You See What You Get? Medical subject headings and their organizing work in the violence against women research, Knowledge Organization, 38, 381-97.

Miller, C. (2017). 'Don't Tell Me There Are No Answers': the information needs and preferences of people living with dementia, University of Strathclyde.

Neal, D. R. and McKenzie, P. (2011) Putting the Pieces Together: endometriosis blogs, cognitive authority and collaborative information behavior, Journal of the Medical Library Association, 99, 127-34.

O'Brien, H. and Cairns, P. (eds) (2016) Why Engagement Matters: cross-disciplinary perspectives of user engagement in digital media, Springer.

O'Connor, B. C. and Wyatt, R. B. (2004) Photo Provocations: thinking in, with and about photographs, Scarecrow Press. 
Pennington, D. R. (2016) Supporting Workplace Information Needs of People with Dementia. In SIG USE/SIG SI Symposium - Information Behavior in Workplaces, Annual Meeting of the Association for Information Science \& Technology (Annual Meeting 2016), Copenhagen, Denmark.

Pierce, R. (2010) A Changing Landscape for Advance Directives in Dementia Research, Social Science \& Medicine, 70, 623-30.

Polkinghorne, S. and Chambers, T. (2016) What Is Known from the Existing Literature about How People Are Informed by Their Own Bodies? SIG USE/SIG SI Symposium Information Behavior in Workplaces, Annual Meeting of the Association for Information Science \& Technology (Annual Meeting 2016), Copenhagen, Denmark. Quinn, C., Anderson, D., Toms, G., Whitaker, R., Edwards, R. T., Jones, C. and Clare, L. (2014) Self-Management in Early-stage Dementia: a pilot randomised controlled trial of the efficacy and cost-effectiveness of a self-management group intervention (the SMART Study), Trials, 15, https://dx.doi.org/10.1186/2F1745-6215-15-74.

RDF Working Group (2014) RDF, www.w3.org/RDF.

Riley, P., Alm, N. and Newell, A. (2008) An Interactive Tool to Promote Musical Creativity in People with Dementia, Computers in Human Behavior, 25, 599-608.

Ritchie, L., Banks, P., Danson, M., Tolson, D. and Borrowman, F. (2015) Dementia in the Workplace: a review, Journal of Public Mental Health, 14, 24-34.

Robertson, J. and Evans, D. (2015) Evaluation of a Workplace Engagement Project for People with Younger Onset Dementia, Journal of Clinical Nursing, 24, 2331-39. Robinson, C. A., Bottorff, J. L., Pesut, B., Oliffe, J. L. and Tomlinson, J. (2014) The Male Face of Caregiving: a scoping review of men caring for a person with dementia, American Journal of Men's Health, 8, 409-26.

Rodgers, P. A. (2017) Co-designing with People Living with Dementia, CoDesign: International Journal of CoCreation in Design and the Arts, http://dx.doi.org/10.1080/15710882.2017.1282527.

Santini, Z. I., Koyanagi, A., Tyrovolas, S., Haro, J. M., Fiori, K. L., Uwakwa, R., Thiyagarajan, J. A., Webber, M., Prince, M. and Prina, A. M. (2015) Social Network Typologies and Mortality Risk among Older People in China, India and Latin America: a 10/66 Dementia Research Group population-based cohort study, Social Science \& Medicine, 147, 134-143.

Span, M., Hettinga, M., Vernooij-Dassen, M., Eefsting, J. and Smits, C. (2013) Involving People with Dementia in the Development of Supportive IT Applications: a 
systematic review, Ageing Research Reviews, 12, 535-51.

Stuart, D. (2016) Practical Ontologies for Information Professionals, Facet Publishing.

Swall, A., Ebbeskog, B., Hagelin, C. L. and Fagerberg, I. (2015). Can Therapy Dogs Evoke Awareness of One's Past and Present Life in Persons with Alzheimer's Disease?, International Journal of Older People Nursing, 10, 84-93.

Toseland, R. W., McCallion, P., Gerber, T. and Banks, S. (2002) Predictors of Health and Human Services Use by Persons with Dementia and their Family Caregivers, Social Science \& Medicine, 55, 1255-66.

UN News Centre (2015) Countries Urged to Make Dementia Public Health Priority as UN Conference Opens in Geneva, www.un.org/News/dh/pdf/english/2015/16032015.pdf.

Van Gorp, B. and Vercruysse, T. (2012) Frames and Counter-frames Giving Meaning to Dementia: a framing analysis of media content, Social Science \& Medicine, 74, 1274 81.

Vernooij-Dassen, M., Wester, F., Auf Den Kamp, M. and Huygen, F. (1998) The Development of a Dementia Process within the Family Context: the case of Alice, Social Science \& Medicine, 47, 1973-80.

Wilson, R. S. (2005) Mental Challenge in the Workplace and Risk of Dementia in Old Age: is there a connection?, Occupational and Environmental Medicine, 62, 72-3.

World Health Organization (2017) Dementia: a public health priority, www.who.int/mental_health/neurology/dementia/infographic_dementia.pdf?ua=1.

Yan, L. and Tan, Y. (2014) Feeling Blue? Go online: an empirical study of social support among patients, Information Systems Research, 25, 690-709.

Yates, C. (2015) Exploring Variation in the Ways of Experiencing Health Information Literacy: a phenomenographic study, Library \& Information Science Research, 37, $220-27$.

Zhang, Y., Sun, Y. and Xie, B. (2015) Quality of Health Information for Consumers on the Web: a systematic review of indicators, criteria, tools and evaluation results, Journal of the Association for Information Science \& Technology, 66, 2071-84. 
